\title{
Stereotypy and variation of the mating call in the Lusitanian toadfish, Halobatrachus didactylus
}

\author{
Maria Clara P. Amorim • José Miguel Simões • \\ Vitor C. Almada $\cdot$ Paulo J. Fonseca
}

Received: 8 April 2010 /Revised: 13 September 2010 /Accepted: 4 October 2010 /Published online: 19 October 2010

(C) Springer-Verlag 2010

\begin{abstract}
Signal attributes should show different degrees of variability depending on the information to be conveyed. Species identity is usually associated with stereotyped features of a signal, whereas other types of information such as individual quality and motivation are associated with signal plasticity. Lusitanian toadfish males form aggregations during the breeding season and emit a tonal advertisement call (the boatwhistle) to attract mates to their nests. We test the hypothesis that the boatwhistle can convey information both on individual identity and motivation by checking how signal parameters vary with time. We study how the physical (tide level) and social (calling alone or in a chorus) environments and male calling rate affect this advertisement signal and how all these external and internal factors (environment, social and male motivation) blend to modulate the Lusitanian toadfish's advertisement call. Boatwhistles of each male were very stereotyped in short periods of time (minutes), but intra-male signal variability greatly increased in a longer time scale (days). Nevertheless, significant differences among males could still be found even in a long time scale. Pulse period was the acoustic feature that most contributed to discriminate among males. Tide level and male calling rate modulated
\end{abstract}

Communicated by V. Janik

M. C. P. Amorim $(\bowtie) \cdot J$. M. Simões • V. C. Almada

Unidade de Investigação em Eco-Etologia,

Instituto Superior de Psicologia Aplicada,

Rua Jardim do Tabaco 34,

1149-041 Lisbon, Portugal

e-mail: amorim@ispa.pt

\section{P. J. Fonseca}

Departamento de Biologia Animal e Centro de Biologia

Ambiental, Faculdade de Ciências da Universidade de Lisboa,

Bloco C2, Campo Grande,

1749-016 Lisbon, Portugal boatwhistle characteristics, and there was a differential effect of tide on call attributes depending on male calling rate. Social acoustic environment only affected calling rate. These results suggest that inter-individual differences in call characteristics and call plasticity may mediate both malemale assessment and mate choice.

Keywords Acoustic communication · Individuality - Signal plasticity $\cdot$ Batrachoididae $\cdot$ Teleost fish $\cdot$ Tide effects

\section{Introduction}

Animals use acoustic signals to convey different types of information such as species identity, individual identification, condition, sexual or aggressive motivation and territorial ownership. The variability of spectral and temporal features contained in different calls or in a single call may convey different types of messages. For example, signal attributes that convey a species' identity show little variation among individuals within a species. Conversely, acoustic features that convey individual identity evidence strong stereotypy within an individual but show larger variation between individuals (Bee et al. 2001). Additionally, features such as signal repetition rate or intensity may indicate motivation or condition and thus provide fundamental information for mate choice and for male-male interactions (Bradbury and Vehrencamp 1998).

In species in which males defend territories in complex spacing systems to obtain mates, such as in male calling aggregations, advertisement acoustic signals should inform receivers about species and sex identity, sender's location, motivation and individual quality (Bradbury and Vehrencamp 1998). These different messages can be communicated in some species by large and complex 
acoustic repertoires while other species may exhibit more limited repertoires and rely on the plasticity of certain call features (e.g. Burmeister et al. 1999). Consequently, species with small repertoires can be excellent models to understand the interplay between variable and more stereotyped signal features not only conveying species identity but also mediating male-male competition and mate choice.

Many teleost fish species rely on their calls to acquire mates (e.g. Malavasi et al. 2003) and to keep intruders away from their territories (Ladich and Myrberg 2006). Teleost fish produce relatively simple sounds in small acoustic repertoires (Amorim 2006) and in a few species the vocal motor networks and the auditory systems have been well studied (Bass and Mckibben 2003). Hence, teleosts provide simple models to study the role of acoustic signals in reproductive and agonistic decisions in vertebrates.

Fish from the family Batrachoididae (toadfishes and midshipmen) have emerged as one of the groups where acoustic communication is best studied in this taxon (Bass and Mckibben 2003). During the breeding season, male batrachoidids produce advertisement calls (boatwhistles or hums) from their nests that are important for regulating male spacing and for mate attraction (Fish 1972; Brantley and Bass 1994). Nesting males form clusters and vocalise close together in a chorus (Bass 1996; Amorim et al. 2006). The gulf toadfish (Opsanus beta) changes calling rate and sound duration both during territorial intrusions and during increased crepuscular chorus activity, thus depicting a remarkable ability for teleost fishes to modulate calls according to the social context (Thorson and Fine 2002; Remage-Healey and Bass 2005). Further, a recent study based on passive acoustics has shown that the boatwhistles of the Lusitanian toadfish Halobatrachus didactylus are highly stereotyped and show individual differences when considering short time periods (5-10 min) (Amorim and Vasconcelos 2008). Individuality in fish vocalisations is unusual and has only been mentioned for batrachoidids and fishes of the Mormyridae family (Crawford et al. 1997; Amorim and Vasconcelos 2008; but see also Myrberg et al. 1993). Calling rate and acoustic features of batrachoidids' vocalisations are also affected by environmental factors such as water temperature and lunar cycles (Brantley and Bass 1994; Maruska and Mensinger 2009). In summary, previous studies suggest that the batrachoidid advertisement call may carry different messages in one relatively simple signal.

Male Lusitanian toadfish nest frequently in intertidal estuarine areas and are thus faced with fluctuating environmental parameters, such as water level and temperature, which may directly affect acoustic communication. In fact, temperature influences muscle contraction and thus may affect sound production (Connaughton et al. 2000). Sound propagation is highly influenced by tide, since not only the sound attenuation increases significantly with lowering water level (Fine and Lenhardt 1983; Mann 2006) but also background noise often changes with tide. Because mate attraction in this species relies on a single call type that is broadcasted in a physically variable and acoustically complex environment, it provides an excellent model to study how environmental and social factors affect the variability of this advertisement signals. Here, we test the hypothesis that the advertisement call of the Lusitanian toadfish shows enough inter-male variability and intra-male plasticity to convey information of male identity and motivation in chorusing aggregations. We registered vocalisations from groups of Lusitanian toadfish in an intertidal area to examine individual differences (stereotypy) among well-identified Lusitanian toadfish males in different time spans, from minutes to 1 week. We examined how environmental constraints (tide level), male calling rate and social environment modulate the Lusitanian toadfish's advertisement call and discuss the possible role of signal stereotypy and plasticity.

\section{Material and methods}

\section{Study species}

The Lusitanian toadfish, H. didactylus (Batrachoididae) is a benthic marine fish that inhabits coastal areas and brackish environments from the Gulf of Guinea to the Tagus estuary, Portugal, appearing occasionally up to the Bay of Biscay (Roux 1986). Breeding males build nests under rocks in shallow water and attract females to spawn with long advertisement calls (boatwhistles) from May to July, forming conspicuous choruses (dos Santos et al. 2000; Amorim et al. 2006). Females show low fecundity since they lay only a few hundreds of large eggs in a single batch on the roof of a nest (Modesto and Canário 2003; Costa 2004) whose survival is assured through male parental care.

Sound recording and analysis

We deployed 60 artificial concrete shelters every $1.5 \mathrm{~m}$ in rows along the shoreline in an intertidal area of the Tagus estuary (Portugal, Montijo, Air-Force Base 6; $38^{\circ} 42^{\prime} \mathrm{N}, 8^{\circ}$ $\left.58^{\prime} \mathrm{W}\right)$. The shelters had a hemicylinder shape capped at one end (internal dimensions, $50 \mathrm{~cm}$ long, $30 \mathrm{~cm}$ wide and $20 \mathrm{~cm}$ high) and were readily occupied by toadfish in the breeding season. These nests were only exposed to air during spring low tides. The water level in the nesting area varied between $0 \mathrm{~m}$ and $2.8 \mathrm{~m}$. Three groups of six to eight males $(n=22)$ that spontaneously occupied these artificial 
concrete nests were recorded over a period of 8 days in June/July 2006 and 2007, during the peak of the reproductive season. Subject males had a mean total length of $42.9 \mathrm{~cm}$ (range, 37.9-47.7 cm) and a mean eviscerated weight of 1,207 g (857-1,612 g). Each male was recorded for an average of $35 \mathrm{~h}(11-56 \mathrm{~h})$. Nests with the subject fish were placed $1.5 \mathrm{~m}$ apart in two rows and were at least $15 \mathrm{~m}$ apart from other nests that could be occupied by other males. Nests' entrances were closed with a plastic mesh that allowed prey items to enter but prevented males from abandoning the nest during recordings. The plastic mesh did not affect acoustic signals and allowed possible visual interactions. One hydrophone (High Tech 94 SSQ hydrophone, sensitivity $-165 \mathrm{~dB}$ re $1 \mathrm{~V} / \mu \mathrm{Pa}$, frequency response within $\pm 1 \mathrm{~dB}$ from $30 \mathrm{~Hz}$ to $6 \mathrm{kHz}$ ) was placed at about $10 \mathrm{~cm}$ from the entrance of each subject male's nest and about $10 \mathrm{~cm}$ from the substrate. Simultaneous multi-channel recordings were made to a laptop connected to USB audio capture devices (Edirol UA25, Roland; 16 bit, $6 \mathrm{kHz}$ acquisition rate per channel) controlled by Adobe Audition 2.0 (Adobe Systems Inc., 2005). Recorded sounds could be attributed to each male due to the high acoustic attenuation observed in the simultaneous multi-channel recordings between neighbouring males. Water temperature was measured every $3 \mathrm{~h}$ during recording periods and averaged $23^{\circ} \mathrm{C}$ (range, $19.5-28^{\circ} \mathrm{C}$ ). All subject fish experienced similar water temperature variability during recordings.

Boatwhistles have been described in detail in Amorim and Vasconcelos (2008). This sound has a variable duration from a few hundred milliseconds up to over a second and is composed of three different segments or phases characterised by different durations, pulse periods, relative amplitude and dominant frequencies (Amorim and Vasconcelos 2008). The tonal phase (P2) of the boatwhistle is the longest and the most characteristic of boatwhistles in the Lusitanian toadfish and in other batrachoidids (Thorson and Fine 2002; Amorim and Vasconcelos 2008). We analysed boatwhistles for total sound duration (milliseconds, measured from the start of the first pulse to the end of the last pulse), pulse period of the tonal segment P2 (milliseconds, average peak to peak interval of six consecutive pulses in the middle of P2), dominant frequency of P2 (hertz, the frequency with maximum energy in $\mathrm{P} 2$ ), dominant frequency modulation (the ratio of the dominant frequencies of the initial and the tonal phases) and amplitude modulation (the ratio of the mean amplitude of the initial and the tonal phases). These acoustic parameters are depicted in Fig. 1. A previous study has shown that these are the most important acoustic parameters to discriminate among individuals (Amorim and Vasconcelos 2008). Sound analysis was carried out with Adobe Audition 2.0 and Raven 1.2.1 for Windows (Bioacoustics Research Program, Cornell Laboratory of Ornithology, Ithaca, NY, USA).
Note that since the hydrophones were just $10 \mathrm{~cm}$ away from the calling males, any detected effects of tide level on acoustic parameters were not related to water level transmission loss dependence (see for example Fine and Lenhardt 1983; Mann 2006).

\section{Statistical analysis}

We calculated the mean and standard deviation (SD) for each of the five boatwhistle acoustic variables emitted by 13 males in two time frames: short, 10 boatwhistles per male emitted over a time period of no longer than $10 \mathrm{~min}$; long, mean of 41 (range, 11-95) boatwhistles per male produced during up to 8 days. We subsequently computed the overall means and SDs for each acoustic variable using the previously calculated mean values for each male. We determined the within-male variability for the five acoustic variables by calculating the within-male coefficient of variance $\left(\mathrm{CV}_{\mathrm{w}}=\mathrm{SD} /\right.$ mean $)$ for each male and subsequently computed the mean for all males. We also determined the between-male coefficient of variation $\left(\mathrm{CV}_{\mathrm{b}}\right)$ by dividing the overall $\mathrm{SD}$ by the respective overall mean. The ratio $\mathrm{CV}_{\mathrm{b}} /$ $\mathrm{CV}_{\mathrm{w}}$ was then calculated to obtain a measure of relative between-male variability for each boatwhistle feature. When this ratio is larger than one, it suggests that the acoustic parameter is more variable between individuals relative to its variability within individuals and could be used as a cue for individual discrimination (Christie et al. 2004). KruskalWallis tests were computed to compare differences among males for each acoustic feature in the two time frames.

Discriminant function analysis (DFA) was carried out as a multivariate tool to determine if males could be discriminated based on their sounds considering these five acoustic variables and to verify which acoustic features better distinguish males. DFA also gives a measure of discrimination accuracy by revealing the percentage of sounds correctly assigned to each individual (Mundry and Sommer 2007). DFA were performed both on the short time frame (ten boatwhistles per male emitted within 10 min by 14 males) and on the longer time frame (ten boatwhistles per male emitted during up to 8 days by the same males, $n=13$ ) data sets. Data were standardised $[(x i-m e a n) / S D]$ to remove differences of magnitude observed between individuals for a given acoustic parameter. We confirmed that DFA assumptions were met with the inspection of residual plots (predicted vs residuals values, normal probability plots), by performing Levene's and the multivariate Box $M$ tests for homogeneity of variances/covariances and by checking tolerance levels to assess possible multicollinearity among variables. In addition, to validate the models obtained, a cross-validation method ('leave-one-out') was carried out (Mundry and Sommer 2007). In this method each sound is classified by the discriminant functions derived by the $n-1$ remaining sounds. 
Fig. 1 Oscillogram (a), sonogram (b) and power spectrum (d) of a boatwhistle. Sound duration (thick continuous line), the initial phase (P1, fine continuous line) and the tonal phase (P2, fine dashed line) of the boatwhistle are depicted in the oscillogram. Dominant frequency $(D F)$ of the tonal phase is shown in the sonogram and in the power spectrum. Detail of the boatwhistle tonal phase waveform depicting the pulse period $(P P)(\mathbf{c})$

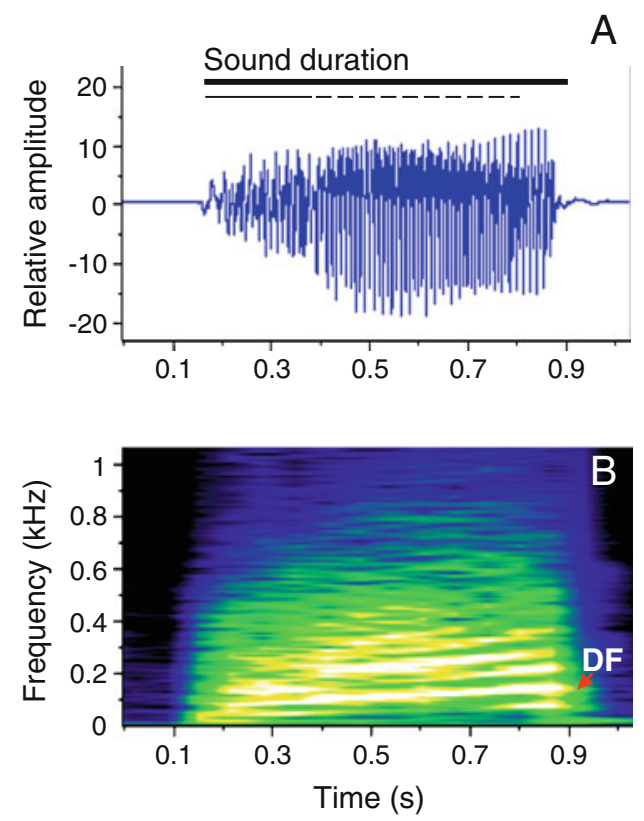

A
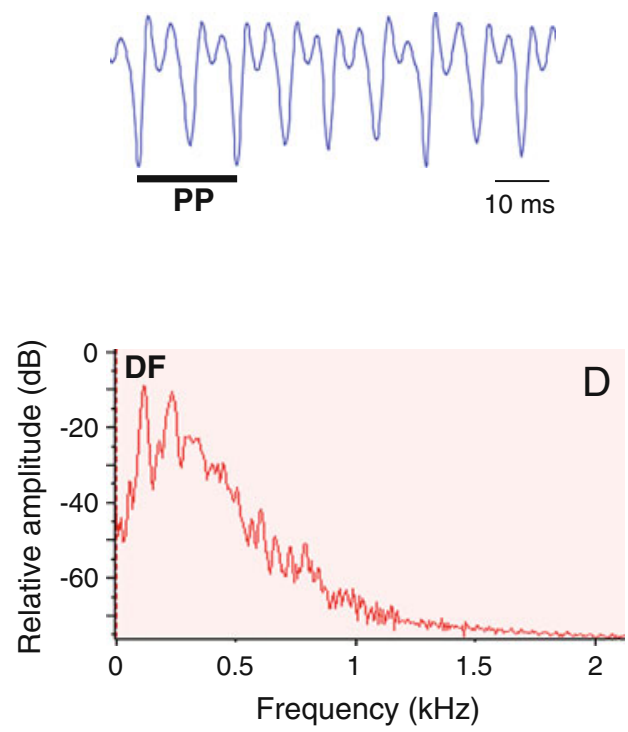

We also tested whether environmental and social factors and male calling rate had a significant effect in boatwhistle acoustic variables in a long time frame with multi-way analysis of covariance (ANCOVA). In this analysis, we used sounds registered in the longest possible time span per individual (up to 8 days) and during different tide levels and social environments. We considered an average of 34 sounds per male (range $=10-92$ ) for 16 males. As data was unbalanced ANCOVA were based on sum of squares III. Tide level was included as a factor with three levels: $1=$ full tide, $2=\mathrm{ebb}$ tide and $3=$ low tide. Rising tide was not considered because of the reduced number of males calling during this tide level, which was significantly lower than at high and ebb tide, and lower, although not significantly, than low tide (Kruskal-Wallis test, $n=190, H=26.11, p<$ 0.001; Fig. 2). Social environment was another factor with two levels: $1=$ calling alone and $2=$ calling in a chorus of at least two males. We included a third factor with two levels that represented male's calling rate $\left(1=\right.$ low rate $<9 \mathrm{BWmin}^{-1}$ and $2=$ high rate $\left.\geq 9 \mathrm{BWmin}^{-1}\right)$. Nine number of boatwhistles per minute $\left(\mathrm{BWmin}^{-1}\right)$ was considered the cutpoint since the average calling rate for all fish was of $8.8 \mathrm{BWmin}^{-1}(n=576)$. This factor was included because exploratory analysis showed calling rate affected call features. We also considered calling rate as a dependent variable. In this case only tide and social factors were included in the models. Water temperature was included as a continuous variable (covariate) because it can influence acoustic parameters (Amorim et al. 2006). When the effect of this covariate was not significant, multi-way ANOVA were carried out instead. The final models complied with normality and homogeneity of variance assumptions. We also confirmed the absence of multicollinearity between the predictors (variance inflation factors were always smaller than
5 and tolerance levels larger than 0.1 ; Montgomery et al. 2006) since water temperature tended to be on average $2^{\circ} \mathrm{C}$ higher at low tide than in other tide levels.

Non-parametric statistical tests were carried out when parametric assumptions were not met. Non-parametric statistics and ANCOVA tests were carried out with Statistica (9, Statsoft Inc., USA) and DFA were performed using SPSS (16.0, SPSS Inc., USA) for Windows.

\section{Results}

Stereotypy: short time frame

All five acoustic parameters showed significant differences between individuals (Table 1). There was a strong stereotypy in most acoustic parameters measured, and only the

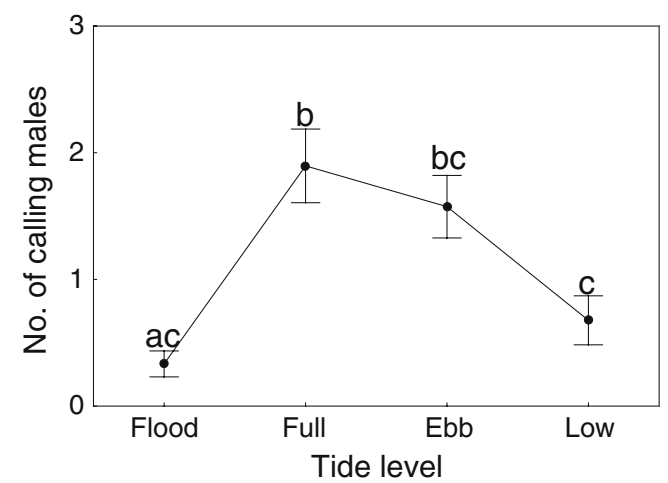

Fig. 2 Variation of the number of calling males $(\max =8)$ with tide levels. Dots and error bars are means and standard errors. Different letters indicate pairwise significant differences given by Dunn tests, i.e. factor levels with the same letter show no significant differences 
Table 1 Within-male variability $\left(\mathrm{CV}_{\mathrm{w}}\right)$ and between-male variability $\left(\mathrm{CV}_{\mathrm{b}}\right)$ for the five acoustic variables analysed from the same 13 Lusitanian toadfish males in a short (up to $10 \mathrm{~min}$ ) and in a long time frame (up to 8 days)

\begin{tabular}{|c|c|c|c|c|c|c|c|c|c|c|}
\hline \multirow[b]{2}{*}{ Acoustic variables } & \multicolumn{5}{|l|}{ Short time frame } & \multicolumn{5}{|l|}{ Long time frame } \\
\hline & $\operatorname{Mean}^{\mathrm{a}}( \pm \mathrm{SD})$ & $\mathrm{CV}_{\mathrm{w}}$ & $\mathrm{CV}_{\mathrm{b}}$ & $\begin{array}{l}\mathrm{CV}_{\mathrm{b}} / \\
\mathrm{CV}_{\mathrm{w}}\end{array}$ & $\mathrm{H}^{\mathrm{b}}$ & $\operatorname{Mean}^{\mathrm{a}}( \pm \mathrm{SD})$ & $\mathrm{CV}_{\mathrm{w}}$ & $\mathrm{CV}_{\mathrm{b}}$ & $\begin{array}{l}\mathrm{CV}_{\mathrm{b}} / \\
\mathrm{CV}_{\mathrm{w}}\end{array}$ & $\mathrm{H}^{\mathrm{c}}$ \\
\hline Sound duration (ms) & $723.1( \pm 161.9)$ & 0.10 & 0.21 & 2.11 & 101.33 & $686.8( \pm 190.2)$ & 0.22 & 0.21 & 0.95 & 147.47 \\
\hline Pulse period P2 (ms) & $18.9( \pm 1.4)$ & 0.02 & 0.07 & 2.92 & 109.9 & $18.5( \pm 1.7)$ & 0.08 & 0.04 & 0.47 & 111.12 \\
\hline $\begin{array}{l}\text { Dominant frequency P2 } \\
(\mathrm{Hz})\end{array}$ & $143.0( \pm 43.0)$ & 0.11 & 0.27 & 2.54 & 95.08 & $127.6( \pm 46.6)$ & 0.31 & 0.23 & 0.73 & 166.53 \\
\hline Frequency modulation & $0.9( \pm 0.3)$ & 0.18 & 0.21 & 1.20 & 63.11 & $0.8( \pm 0.4)$ & 0.46 & 0.21 & 0.47 & 78.7 \\
\hline Amplitude modulation & $0.7( \pm 0.1)$ & 0.04 & 0.11 & 2.49 & 111.17 & $0.7( \pm 0.8)$ & 0.31 & 0.23 & 0.77 & 175.54 \\
\hline
\end{tabular}

Ten boatwhistles were analysed per male for the short time frame analysis, whereas an average of 41 sounds per male (range $=11-95)$ were analysed from the long time frame data set. Note that only 13 individuals are considered since only these are in common in the short and the long time frame analyses data sets. P2, middle tonal phase in the boatwhistle

${ }^{a}$ Results computed for all sounds considered per analysis.

${ }^{\mathrm{b}}$ Results of Kruskal-Wallis tests ( $\left.\mathrm{DF}=12, n=130\right)$ comparing differences between males for each acoustic feature

${ }^{\mathrm{c}}$ Results of Kruskal-Wallis tests $(\mathrm{DF}=12, n=534)$ comparing differences between males for each acoustic feature. All comparisons are significant at $p<0.001$

frequency modulation showed a within-male $\mathrm{CV}_{\mathrm{w}}$ larger than 0.11 (Table 1). Consistently, with the Kruskal-Wallis results, all five acoustic variables were more variable between than within males as all $\mathrm{CV}_{\mathrm{b}} / \mathrm{CV}_{\mathrm{w}}$ ratios were larger than one (Table 1).

A discriminant function analysis (DFA, $n=140$, Wilks' lambda $=0.0004, \mathrm{DF}=65,580, p<0.001)$ assigned boatwhistles to the correct male with an average success of $86 \%$ (range, $30-100 \%$ ). The first two discriminant functions explained $74 \%$ of data variability with $\mathrm{P} 2$ pulse period weighing most heavily in explaining variation in the first function and sound duration and amplitude modulation in the second function (Table 2). After cross-validation the correct classification assigned by the DFA model was similar (80\%).

Taken together, these data reveal that male Lusitanian toadfish show individual differences in the properties of boatwhistle in a time frame of a few minutes.

\section{Variability: long time frame}

Considering a period of time as long as possible for each male (up to 8 days), significant differences between males were kept for all five acoustic parameters (Table 1); however, only the pulse period of $\mathrm{P} 2$ showed a withinmale $\mathrm{CV}$ smaller than 0.1 and all the $\mathrm{CV}_{\mathrm{b}} / \mathrm{CV}_{\mathrm{w}}$ ratios were smaller than one showing that when a long time frame is considered all five acoustic variables become more variable within than between males. A discriminant function analysis ran on this long-term data set (DFA, $n=130$, Wilks' lambda $=0.09, \mathrm{DF}=60,532, p<0.001)$ showed that the average classification success decreased to $45 \%$ (range, 0-90\%) with the first two discriminant functions explaining
$72 \%$ of data variability. The percentage of correct classification after cross-validation (leave-one-out procedure) was $35 \%$. In conclusion, significant differences among male calls in a long time scale were still found, although to a lesser extent than in a short time scale.

Sources of call variability: long time frame

Sound duration decreased significantly during low tide (Table 3; Fig. 3a) and this parameter was also significantly affected by the calling rate. The interaction between the factors calling rate and social environment was significant (Table 3) and sound duration significantly decreased in males calling at a low rate and significantly increased in

Table 2 Standardised canonical DFA coefficients, eigenvalues and cumulative percentage of variance explained by the first two discriminant functions of a DFA classifying 14 Lusitanian toadfish males by their boatwhistles' acoustic characteristics

\begin{tabular}{|c|c|c|}
\hline \multirow[b]{2}{*}{ Discriminant variables } & \multicolumn{2}{|c|}{ Discriminant functions } \\
\hline & First & Second \\
\hline Sound duration (ms) & 0.05 & $0.57^{\mathrm{a}}$ \\
\hline Pulse period P2 (ms) & $0.69^{\mathrm{a}}$ & 0.00 \\
\hline Dominant frequency P2 $(\mathrm{Hz})$ & -0.03 & -0.22 \\
\hline Frequency modulation & -0.25 & 0.07 \\
\hline Amplitude modulation & 0.44 & -0.55 \\
\hline Eigenvalue & 10.53 & 9.21 \\
\hline Cumulative $\%$ of variance & 39.6 & 74.3 \\
\hline
\end{tabular}

Boatwhistles were emitted in a period of $10 \mathrm{~min}$

${ }^{\mathrm{a}}$ Discriminant variable with the highest pooled within-groups correlations with the standardised discriminant functions. 


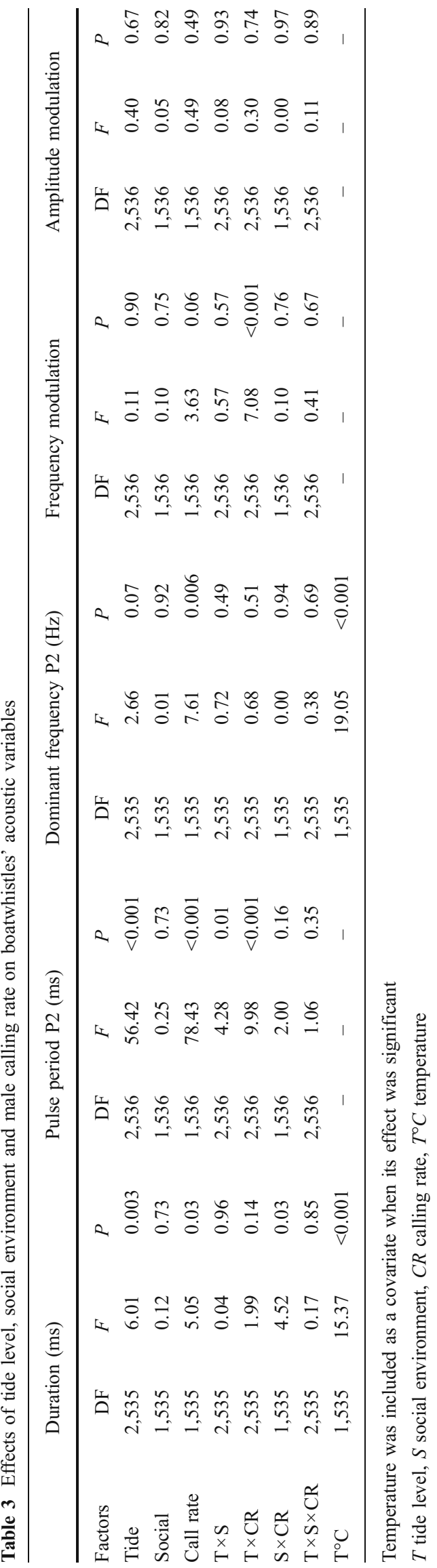

males calling at a high rate with the raise of social complexity, i.e. in a chorus situation (Fig. 3b). There was a difference in sound duration between males calling at high and low rate only when the fish were singing in a chorus (Fig. 3b).

P2 pulse period decreased significantly at low tide (Table 3; Fig. 4). The interaction term between tide and calling rate was significant. The decrease in the pulse period with water level was more marked in males calling at a high rate than at a low rate. Males calling at a high rate had a shorter pulse period in their calls and significant differences between call rate levels were observed at ebb and low tide levels (Fig. 4a). The interaction between tide level and social environment was also significant. Pulse period decreased gradually with water level in males calling alone, but in males calling in groups there was only an abrupt decrease at low tide. There was, however, no significant effect of social environment on pulse period as differences for this parameter between males calling alone or in a chorus were not significant in any tide level (Fig. 4b).

P2 dominant frequency was only significantly affected by calling rate (Table 3 ) and males calling at a high rate showed significantly higher values for this acoustic parameter than males calling at a low rate (Fig. 5).

Only the interaction term between tide level and calling rate had a significant effect on frequency modulation and males calling at a high rate showed higher frequency modulations than less vocal males at ebb tide (Table 3; Fig. 6). There was no significant effect of any variable or interaction term in amplitude modulation (Table 3).

Social environment had an effect in the calling rate (ANCOVA, social environment: $F_{1,541}=42.17, p<0.001$; covariate water temperature, $F_{1,541}=6.16, p=0.01$ ). Data inspection showed that males that call alone mostly call at low rates, but males in a chorus call at all rates. There was a significant effect of the interaction between social environment and tide level (ANCOVA, interaction: $F_{2,541}=11.55$, $p<0.001$, tide level: $F_{2,541}=0.97, p=0.38$ ). Calling rate of males calling alone increased at low tide and with the exception of this tide level it was significantly lower than the calling rate for males in a chorus situation (Fig. 7).

\section{Discussion}

Stereotypy vs. variability

There was strong stereotypy in the boatwhistles produced by Lusitanian toadfish males when considering periods of 10 min consistent with the study of Amorim and Vasconcelos (2008) based on unidentified fish. Males differed significantly in all five acoustic parameters and 

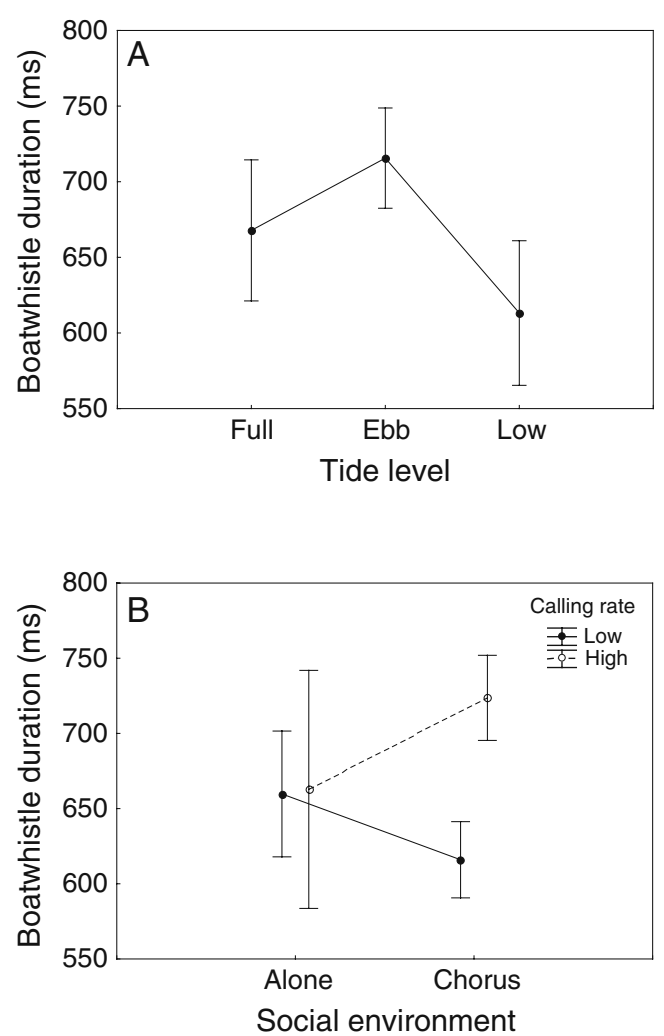

Fig. 3 Effect of tide level on boatwhistle duration (a). Effect of social environment (calling alone or in a chorus) and male calling rate (low rate, filled circle and high rate, open circle) on sound duration (b). Circles are means computed for the covariate water temperature mean and error bars are $95 \%$ confidence intervals

average correct classification of individuals based on their calls was high $(86 \%)$ as shown by DFA, with P2 pulse period, sound duration and amplitude modulation being the best parameters to discriminate among males. Individual differences in signals are important to mediate social interactions, namely between neighbouring territorial males (Bradbury and Vehrencamp 1998). Individual recognition is especially relevant when animals defend long-term territories, such as breeding Lusitanian toadfish males do, because territory holders can reduce aggression towards familiar neighbours, which are less likely to intrude their territories ('dear enemy effect', Temeles 1994). Although this effect was not yet identified in toadfishes, examples exist in several taxa. For instance, territorial male bullfrogs (Rana catesbiana) show individual differences in their advertisement calls that mainly differ in the fundamental frequency (Bee and Gerhardt 2001a). Playback experiments have shown that this acoustic parameter mediates neighbour-stranger recognition in this species since they show less aggression in response to familiar calls (Bee and Gerhardt 2001b).

When considering a longer time frame (up to a week) there were still significant differences among Lusitanian
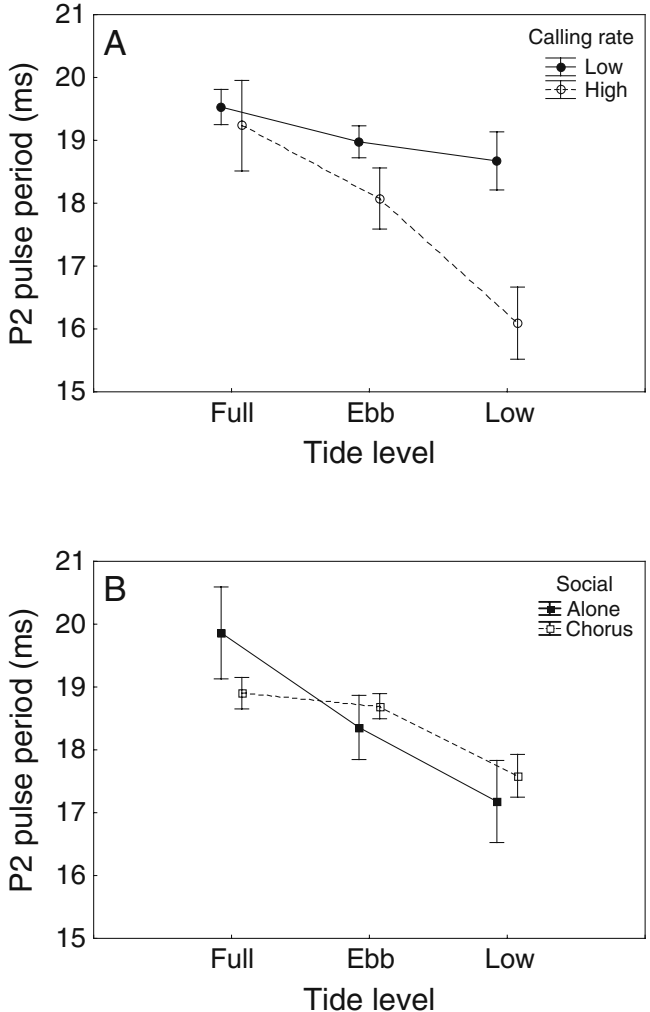

Fig. 4 Effect of tide level and male calling rate (low rate, filled circle and high rate, open circle) (a) and of tide level and social environment (alone, filled square and chorus, open square) on P2 pulse period (b). Circles and squares are means and error bars are $95 \%$ confidence intervals

toadfish males for all five acoustic features, but these become more variable within a male (Table 1). With the exception of P2 pulse period, all other parameters showed high intra-male variability over a week. This variability of the Lusitanian toadfish advertisement calls in a longer time frame suggests that boatwhistles are being modulated by either external factors such as the physical or the social environment or by

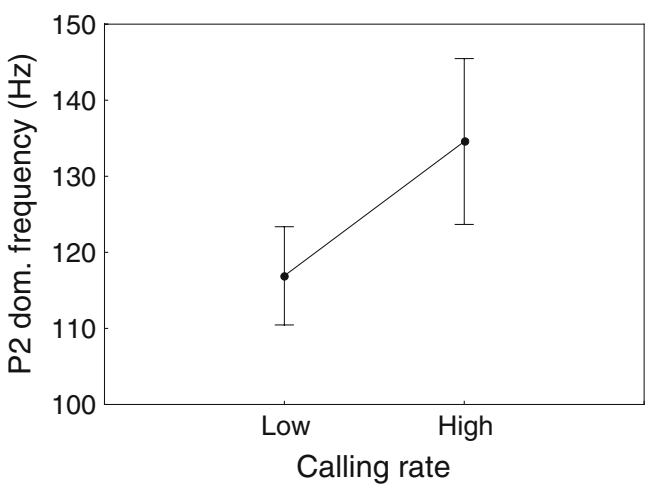

Fig. 5 Effect of male calling rate on P2 dominant frequency. Dots are means computed for the covariate water temperature mean and error bars are $95 \%$ confidence intervals 


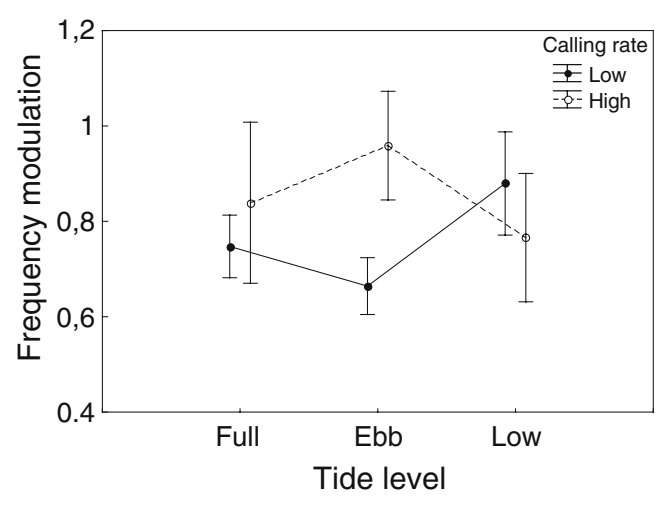

Fig. 6 Effect of tidal level and male calling rate (low rate, filled circle and high rate, open circle) on dominant frequency modulation. Circles and error bars are means and $95 \%$ confidence intervals

internal factors such as the internal physiological state of the male (Remage-Healey and Bass 2005).

Interestingly, the $\mathrm{P} 2$ pulse period was the least variable acoustic feature both within and between males and kept the $\mathrm{CV}_{\mathrm{w}}$ and $\mathrm{CV}_{\mathrm{b}}$ under 0.1 , regardless of the time span considered. Pulse period corresponds to the sonic muscle contraction period (Skoglund 1961; Fine et al. 2001), which is controlled by central vocal pattern generators in batrachoidids, and is stereotyped at the species level (Bass and McKibben 2003); nevertheless, $\mathrm{P} 2$ pulse period was the parameter that contributed the most to discriminating among individuals in a short time scale (DFA) suggesting it presents fine differences among individuals regardless of the time scale considered, which might be used for individual recognition among neighbouring nesting males.

P2 pulse period could also be indicative of male quality. In a recent study, Amorim et al. (2010) found that in the Lusitanian toadfish the pulse period reflects male condition and males with a higher body lipid content produced vocalisations with shorter pulse periods. These authors suggested that males that contract the sonic muscles at a very fast rate could reliably be indicating to neighbouring males or females their better

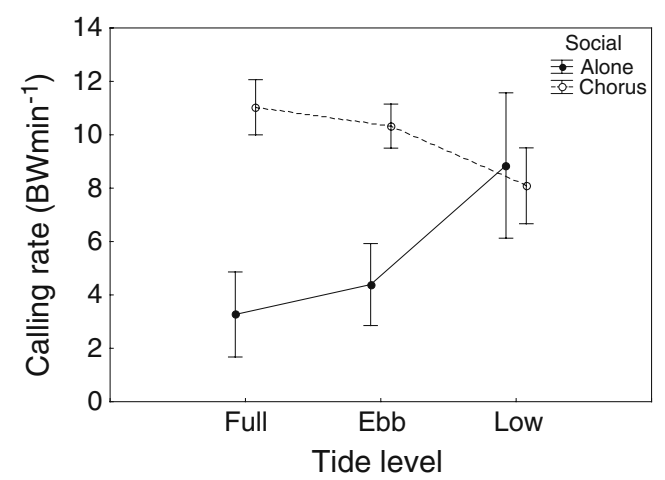

Fig. 7 Effect of tidal level and social environment (alone, filled circle and chorus, open circle) on calling rate. Circles are means computed for the covariate water temperature mean and error bars are $95 \%$ confidence intervals quality (condition) with the ability to sustain sonic muscle contraction close to their physiological limit. Consistently, males of the nonpasserine bird Brown Skuas that produce long difficult calls close to their performance limit are honestly advertising a higher breeding success (Janicke et al. 2008).

\section{Sources of variability}

Tide level had a significant effect in boatwhistle duration and P2 pulse period, which showed lower values at low tide. Consequently, vocal conspicuity was reduced at low tide as the number of calling males (see "Material and methods") and sound duration decreased. A decrease of calling effort at low tide is expected because low frequency sounds attenuate very rapidly in low water levels and the chance of being detected by distant females is reduced (Fine and Lenhardt 1983; Mann 2006). Nevertheless, males that were calling at a high rate showed a pronounced increase of the fundamental frequency (the inverse of the pulse period) with low tide thus increasing the chances of sound detection at low water levels (Mann 2006). To the best of our knowledge, the effect of tide levels on fish vocalisations has not been studied before, but Barimo and Fine (1998) have mentioned that oyster toadfish increase calling on incoming tide, suggesting that as other intertidal fish, batrachoidids may have endogenous activity rhythms related to tides with lowest levels of activity at low tide (Gibson 1982). Future work should address the stability of call rate and characteristics in Lusitanian toadfish males that inhabit deeper areas and are less subject to the harsh fluctuating physical environment of the intertidal area.

Social environment affected calling rate in the Lusitanian toadfish and chorusing males called at higher rates. Accordingly, calling rate is influenced by the vocal behaviour of nearby male conspecifics in other batrachoidids (Winn 1967; Fish 1972; Remage-Healey and Bass 2005). For example, Gulf toadfish males when experimentally placed in an active calling environment started to vocalise within $48 \mathrm{~h}$ (RemageHealey and Bass 2005). Males in a chorus probably benefit from increased mate attraction, reduced assessment costs or reduced predation risks, although experimental evidence supporting these hypotheses is scarce (Gerhardt and Huber 2002). We have also observed that high-calling-rate and probably more motivated Lusitanian toadfish males produced longer boatwhistles than low-calling rate males, but only when singing in a chorus. Burmeister and Wilczynski (2001) examined the influence of androgens on calling behaviour in the presence and the absence of social acoustic signals in male green treefrogs (Hyla cinerea) and concluded that the influence of androgens on the motivation to call depended on the social stimuli. It is likely that also in the Lusitanian toadfish, androgens have a differential effect in boatwhistle acoustic features, namely duration, dependent on social stimuli. 
Male calling rate also had a significant effect on acoustic features of boatwhistles. High-calling rate males produced on average longer boatwhistles with higher fundamental frequencies. The higher calling rate and associated longer sound durations observed in the Lusitanian toadfish could be related to higher levels of circulating steroid hormones such as 11 -ketotestosterone $(11 \mathrm{KT})$, which is a teleost-specific androgen (Remage-Healey and Bass 2006). Neurophysiological experiments have shown that steroid hormones exert a rapid and complex neuromodulatory effect in the activity of the vocal pattern generator and in the vocal behaviour of batrachoidids, modulating calling rate and call duration (Remage-Healey and Bass 2003, 2004, 2006). Also, nesting batrachoidid males have elevated $11 \mathrm{KT}$ during vocal advertisement compared to non-calling periods (Knapp et al. 2001; Remage-Healey and Bass 2005). In addition, batrachoidid males presented higher calling rate, call duration and elevated levels in circulating $11 \mathrm{KT}$ after experiencing a territorial intrusion simulated by playback (Remage-Healey and Bass 2005). In this context, Lusitanian toadfish males with higher calling rates and longer sounds could reliably advertise high circulating androgen levels, which also mediates aggressive behaviour (social status) and reproduction (Remage-Healey and Bass 2006). Moreover, calling rate reflects male condition (body lipid content) in this species (Amorim et al. 2010), suggesting that calling rate and associated call features could be advertising male quality traits that are important for social status, territorial defence and possibly parental ability (Andersson 1994). From the female perspective, females that would choose males based on their vocal behaviour could both gain direct benefits (such as enhanced male parental care and better territories for the development of their offspring) and indirect (genetic) benefits (Andersson 1994).

In conclusion, our study has shown that the advertisement calls of the Lusitanian toadfish differ among individuals even when considering several days, but high stereotypy is found only in P2 pulse period when considering longer periods of time. Differences in this parameter could promote individual recognition and also advertise male quality if only some males can perform close to the physiological limit. Our study has also produced evidence to support the acoustic plasticity hypothesis since calling rate seems to be one of the major factors influencing boatwhistle characteristics and could be informative about male motivation and physiological condition (i.e. male quality). The social acoustic environment, on the other hand, seems to mainly influence calling rate (vocal facilitation). We suggest that absolute differences in calling rate and in call characteristics (mainly P2 pulse period, dominant frequency and sound duration), together with the differential way in which tide modulates boatwhistles according to male's motivation level may be used in male-male assessment and in mate choice by females.
Acknowledgements We would like to thank Air Force Base No. 6 of Montijo (Portugal) for allowing this study in their military establishment. This research was funded by the Science and Technology Foundation, Portugal (project PDCT/MAR/58071/2004, pluriannual programmes UI\&D 331/94 and UI\&D 329, grants SFRH/ BPD/14570/2003 and SFRH/BPD/41489/2007).

\section{References}

Amorim MCP (2006) Diversity of sound production in fish. In: Ladich F, Collin SP, Moller P, Kapoor BG (eds) Communication in fishes. Science Publishers, Enfield, pp 71-105

Amorim MCP, Vasconcelos RO (2008) Variability in the mating calls of the Lusitanian toadfish Halobatrachus didactylus: potential cues for individual recognition. J Fish Biol 72:13551368

Amorim MCP, Vasconcelos RO, Marques JF, Almada F (2006) Seasonal variation of sound production in the Lusitanian toadfish, Halobatrachus didactylus. J Fish Biol 69:1892-1899

Amorim MCP, Simões JM, Mendonça N, Bandarra NM, Almada VC, Fonseca PJ (2010) Lusitanian toadfish song reflects male quality. J Exp Biol 213:2997-3004

Andersson M (1994) Sexual Selection. Princeton University Press, Princeton

Barimo JF, Fine ML (1998) The relationship of swimbladder shape to the directionality pattern of underwater sound in the oyster toadfish. Can J Zool 76:134-143

Bass AH (1996) Shaping brain sexuality. Am Sci 84:352-363

Bass AH, McKibben JR (2003) Neural mechanisms and behaviors for acoustic communication in teleost fish. Progr Neurobiol 69:1-26. doi:10.1016/S0301-0082(03)00004-2

Bee MA, Gerhardt HC (2001a) Neighbour-stranger discrimination by territorial male bullfrogs (Rana catesbeiana): I. Acoustic basis. Anim Behav 62:1129-1140

Bee MA, Gerhardt HC (2001b) Neighbour-stranger discrimination by territorial male bullfrogs (Rana catesbeiana): II. Perceptual basis. Anim Behav 62:1141-1150

Bee MA, Kovich CE, Blackwell KJ, Gerhardt HC (2001) Individual variation in advertisement calls of territorial male green frogs, Rana clamitans: implications for individual discrimination. Ethology 107:65-84. doi:10.1046/j.1439-0310.2001.00640.x

Bradbury JW, Vehrencamp SL (1998) Principles of animal communication. Sinauer Associates, Sunderland

Brantley RK, Bass AH (1994) Alternative male spawning tactics and acoustic signals in the plainfin midshipman fish, Porichthys notatus (Teleostei, Batrachoididae). Ethology 96:213-232

Burmeister SS, Wilczynski W (2001) Social context influences androgenic effects on calling in the green treefrog (Hyla cinerea). Horm Behav 40:550-558. doi:10.1006/hbeh.2001.1723

Burmeister S, Wilczynski W, Ryan MJ (1999) Temporal call changes and prior experience affect graded signalling in the cricket frog. Anim Behav 57:611-618

Christie PJ, Mennill DJ, Ratcliffe LM (2004) Chickadee song structure is individually distinctive over long broadcast distances. Behav 141:101-124

Connaughton MA, Taylor MH, Fine ML (2000) Effects of fish size and temperature on weakfish disturbance calls: implications for the mechanism of sound generation. J Exp Biol 203:15031512

Costa JL (2004) The biology of the Lusitanian toadfish, Halobatrachus didactylus (Bloch and Schneider, 1801) and its role in the structuring and functioning of the biological communities; special reference to the Mira estuary population. Dissertation, University of Lisbon 
Crawford JD, Cook AP, Heberlein AS (1997) Bioacoustic behavior of African fishes (Mormyridae): potential cues for species and individual recognition in Pollimyrus. J Acoust Soc Am 102:1200-1212

dos Santos M, Modesto T, Matos RJ, Grober MS, Oliveira RF, Canario A (2000) Sound production by the Lusitanian toadfish, Halobatrachus didactylus. Bioacoustics 10:309-321

Fine ML, Lenhardt ML (1983) Shallow-water propagation of the toadfish mating call. Comp Biochem Physiol A 76:225-231

Fine ML, Malloy KL, King C, Mitchell SL, Cameron TM (2001) Movement and sound generation by the toadfish swimbladder. $\mathrm{J}$ Comp Physiol A 187:371-379

Fish JF (1972) The effect of sound playback on the toadfish. In: Winn HE, Olla B (eds) Behavior of marine animals, vol 2. Plenum Press, New York, pp 386-434

Gerhardt HC, Huber F (2002) Acoustic communication in insects and anurans: common problems and diverse solutions. The University of Chicago Press, Chicago and London

Gibson RN (1982) Recent studies on the biology of intertidal fishes. Oceanogr Mar Biol Annu Rev 20:363-414

Janicke T, Hahn S, Ritz MS, Peter H-U (2008) Vocal performance reflects individual quality in a nonpasserine. Anim Behav 75:9198

Knapp R, Marchaterre MM, Bass AH (2001) Relationship between courtship behavior and steroid hormone levels in parental male plainfin midshipman fish. Horm Behav 39:335, Abstract

Ladich F, Myrberg AA (2006) Agonistic behaviour and acoustic communication. In: Ladich F, Collin SP, Moller P, Kapoor BG (eds) Communication in fishes, vol 1. Science Publishers, Enfield, pp 121-148

Malavasi S, Torricelli P, Lugli M, Pranovi F, Mainardi D (2003) Male courtship sounds in a teleost with alternative reproductive tactics, the grass goby, Zosterisessor ophiocephalus. Environ Biol Fish 66:231-236

Mann DA (2006) Propagation of fish sounds. In: Ladich F, Collin SP, Moller P, Kapoor BG (eds) Communication in fishes, vol 1. Science Publishers, Enfield, pp 107-120

Maruska KP, Mensinger AF (2009) Acoustic characteristics and variations in grunt vocalizations in the oyster toadfish Opsanus tau. Environ Biol Fish 84:325-337
Modesto T, Canário AVM (2003) Morphometric changes and sex steroid levels during the annual reproductive cycle of the Lusitanian toadfish, Halobatrachus didactylus. Gen Comp Endocrinol 131:220-231

Montgomery DC, Peck EA, Vining GG (2006) Introduction to linear regression analysis, 4th edn. Wiley, New York

Mundry R, Sommer C (2007) Discriminant function analysis with non independent data: consequences and an alternative. Anim Behav 74:965-976

Myrberg AA, Ha SJ, Shamblott H (1993) The sounds of bicolor damselfish (Pomacentrus partitus): predictors of body size and a spectral basis for individual recognition and assessment. J Acoust Soc Am 94:3067-3070

Remage-Healey L, Bass AH (2003) Steroid hormones exert rapid, sexspecific changes in vocal communication signals in gulf toadfish, Opsanus beta. Horm Behav 44:72

Remage-Healey L, Bass AH (2004) Rapid, hierarchical modulation of vocal patterning by steroid hormones. J Neurosci 24:5892-5900

Remage-Healey L, Bass AH (2005) Simultaneous, rapid, elevations in steroid hormones and vocal signalling during playback challenge: a field experiment in Gulf toadfish. Horm Behav 47:297-305

Remage-Healey L, Bass AH (2006) A rapid, neuromodulatory role for steroid hormones in the control of reproductive behavior. Brain Res 1126:27-35

Roux C (1986) Batrachoididae. In: Whitehead PJP, Bauchot ML, Hureau JC, Nielsen J, Tortonese E (eds) Fishes of the Northeastern Atlantic and the Mediterranean, vol III. Unesco, Paris, pp 1360-1361

Skoglund CR (1961) Functional analysis of swimbladder muscles engaged in sound production of the toadfish. J Biophys Biochem Cytol 10(Suppl):187-200

Temeles EJ (1994) The role of neighbours in territorial systems: when are they 'dear enemies'? Anim Behav 47:339-350

Thorson RF, Fine ML (2002) Crepuscular changes in emission rate and parameters of the boatwhistle advertisement call of the gulf toadfish, Opsanus beta. Environ Biol Fish 63:321-331. doi:10.1023/A:1014334425821

Winn HE (1967) Vocal facilitation and the biological significance of toadfish sounds. In: Tavolga WN (ed) Marine Bio-Acoustics, vol 2. Pergamon Press, Oxford, pp 283-304 